\title{
Chemical shift assignment of the alternative scaffold protein IscA
}

\author{
Matija Popovic $^{1} \cdot$ Annalisa Pastore $^{1}$
}

Received: 3 December 2015 / Accepted: 5 February 2016/Published online: 18 February 2016

(C) The Author(s) 2016. This article is published with open access at Springerlink.com

\begin{abstract}
The IscA protein $(11.5 \mathrm{kDa})$ is an essential component of the iron sulphur cluster biogenesis machine. In bacteria, the machine components are clustered in operons, amongst which the most important is the isc operon. Bacterial IscA has direct homologues also in eukaryotes. Like the protein IscU, IscA is thought to assist cluster formation as an alternative scaffold protein which receives the cluster before transferring it further to the final acceptors. Several crystal structures have been published. They all report an IscA dimeric form, although the packing of the protomers in the dimers differs amongst structures. No solution studies have currently been reported. Here we report the ${ }^{1} \mathrm{H},{ }^{13} \mathrm{C}$ and ${ }^{15} \mathrm{~N}$ backbone and side-chain chemical shift assignments of the cluster-free E. coli IscA as a starting point for further studies of the structure and functions of this still poorly characterized protein. We show that IscA exists in solution as an equilibrium between different species. Spectrum assignment was thus challenging given the heterogeneous nature of the sample but doable through judicious choice of selective labelling and concentration dependent studies.
\end{abstract}

Keywords Iron metabolism - Iron sulphur clusters · Metalloproteins $\cdot$ Scaffold protein $\cdot$ Structure

Annalisa Pastore

annalisa.pastore@crick.ac.uk

1 Maurice Wohl Institute, King's College London, 5 Cutcombe Rd., London SE5 9RT, UK

\section{Biological context}

In biology, iron-sulfur clusters are prosthetic groups attached to proteins which provide the cell with an important source of redox potential (Beinert et al. 1997). Iron-sulphur cluster proteins play essential roles in several different pathways, including the Krebs cycle, purine metabolism, gene regulation and several others (Johnson et al. 2005; Xu and Moller 2011; Fontecave 2006). Their assembly is tightly regulated since iron is readily oxidized and can generate free radicals. Sulphur is also a highly toxic elements in several of its forms. To solve this problem and allow an efficient assembly, specific machines have evolved to assist iron-sulfur cluster assembly (for a recent review see Mettert and Kiley 2015). In bacteria, these machines are grouped in operons (Zheng et al. 1998). The isc operon is the central genetic locus for the pathway as it contains genes highly conserved also in high eukaryotes (Lill 2009). A group of about ten proteins are encoded in the operon, amongst which is the promoter IscR, the desulfurase IscS, the scaffold IscU, the two putative chaperones $\mathrm{HscA}$ and $\mathrm{HscB}$, a ferredoxin and Isc A (Roche et al. 2013). While the role of some components is relatively clear, the exact function of IscA remains uncertain. IscA is a relatively small protein which contains three conserved cysteines. It was shown to bind both iron and be able to host the cluster (Zeng et al. 2007; Ding et al. 2007). Cluster loaded IscU readily donates it to IscA suggesting that the latter protein has a higher affinity to the cluster. It was thus proposed to be an alternative scaffold protein (Krebs et al. 2001; Ollagnier-de-Choudens et al. 2001; Bonomi et al. 2005). However, it remains unclear why a second scaffold should be necessary and at which step is IscA required. Different crystal structures of IscA have been solved (Bilder et al. 2004; Cupp-Vickery et al. 2004; 
Morimoto et al. 2006). They all have shown that IscA is a dimer but the interface between protomers is different in some of the structures leaving open the question of which species exists in solution. In one of the structures the resulting packing is non-symmetric. No solution structure exists yet which could clarify this question and provide more information about the function. Here, we report the backbone assignment in solution of IscA as a first step to the characterization in solution of the IscA aggregation state and its interactions with other proteins.

\section{Materials and methods}

\section{Protein production and purification}

The recombinant E. coli IscA (107 residues) was overexpressed in the E. coli host strain BL21 (DE3) using a kanamycin resistant pETM30 vector. Isotopically ${ }^{15} \mathrm{~N}$ - and ${ }^{13} \mathrm{C} /{ }^{15} \mathrm{~N}$-labelled samples were expressed in minimal (M9) medium supplemented with ${ }^{15} \mathrm{~N}$-ammonium sulphate and ${ }^{13} \mathrm{C}$-glucose as the sole sources of nitrogen and carbon respectively. Purification was performed with a three-step protocol which used anion exchange and size exclusion chromatography. In short, the frozen cell pellet was resuspended in the lysis buffer $(20 \mathrm{mM}$ Tris- $\mathrm{HCl}, 0.2 \%$ IGEPAL, $20 \mathrm{mM}$ DTT, pH 7.5 containing EDTA-free protease inhibitor cocktail tablet (Roche) and sonicated. After centrifugation, the supernatant was loaded on a weak anion exchange column (HiTrap DEAE, GE Healthcare) and eluted with a $0-250 \mathrm{mM} \mathrm{NaCl}$ gradient. The crude material containing the protein was diluted to reduce the salt concentration and loaded on a strong anion exchange column (HiTrapQ, GE Healthcare) and eluted with $0-500 \mathrm{mM} \mathrm{NaCl}$ gradient. The eluted protein $(\sim 70 \%$ pure) was gently concentrated using the stirred-cell ultrafiltration system (Amicon, Millipre) and further purified by FPLC size exclusion chromatography (HiLoad 16/600 Superdex 75pg, GE Healthcare). Protein identity and purity was tested by PAGE and mass spectrometry. Because containing only one tyrosine, IscA has a low estimated extension coefficient $\left(1490 \mathrm{M}^{-1} \mathrm{~cm}^{-1}\right)$. Concentrations were estimated by the Bradford assay using a calibration curve created with BSA samples of known concentrations.

\section{NMR spectroscopy}

NMR spectra for resonance assignments were acquired on samples containing ${ }^{15} \mathrm{~N}$ - or ${ }^{15} \mathrm{~N},{ }^{13} \mathrm{C}$-labelled IscA (0.04-0.5 mM) in $20 \mathrm{mM}$ Tris- $\mathrm{HCl} \mathrm{pH} 7.5,150 \mathrm{mM} \mathrm{NaCl}$, $5 \mathrm{mM}$ TCEP, $8 \%{ }^{2} \mathrm{H}_{2} \mathrm{O}$. The spectra were typically recorded at $298 \mathrm{~K}$ using $600,700,800$ and $950 \mathrm{MHz}$ frequency spectrometers, all equipped with triple resonance gradient CryoProbes. HNCA, $\mathrm{HN}(\mathrm{CO}) \mathrm{CA}$, HNCO, $\mathrm{HN}(\mathrm{CA}) \mathrm{CO}$, HNCACB and $\mathrm{HN}(\mathrm{CO}) \mathrm{CACB}$ experiments (Muhandiram and Kay 1994) were recorded in combination with a $3 \mathrm{D}{ }^{15} \mathrm{~N}$-edited NOESY-HSQC experiment to carry out spectral assignment. All spectra were processed using NMRPipe/NMRDraw software (Delaglio et al. 1995) and analyzed using CCPN software (Fogh et al. 2002).

\section{Resonance assignment and deposition}

The overall excellent chemical shift dispersion in IscA HSQC spectra is indicative of a well folded protein. However, all protein samples and especially those above $100 \mu \mathrm{M}$ contained more amide resonances from the expected 118 (Fig. 1a, b). Typically, also the spectra with low heterogeneity contained an excess of amide resonances ( $\sim 136$ peaks including side chain resonances). Most of the extra resonances were less intense than others or their intensities strongly varied with the concentration. After extensive characterization with size exclusion chromatography we concluded that the observed behaviour is caused by formation of dimers and higher species.

In order to reduce protein oligomerizaton we prepared samples in $20 \mathrm{mM}$ Tris- $\mathrm{HCl}$ at different salt concentrations $(\mathrm{NaCl} 0-1000 \mathrm{mM}), \mathrm{pH}$ values (6-8) and high reducent agent concentrations (either $20 \mathrm{mM}$ DTT or $5 \mathrm{mM}$ TCEP). These conditions were kept throughout purification. Nevertheless, the size exclusion chromatograms showed no significant differences when performed at 50,150 or $1000 \mathrm{mM} \mathrm{NaCl}$ concentrations. Accordingly, we did not observe reduction of the number of amide resonances in spectra acquired at different $\mathrm{NaCl}$ concentrations $(50,150$ and $250 \mathrm{mM})$ or at different $\mathrm{pH}$ values $(6.0,7.0,7.5$ and 8$)$.

The best results were obtained when purification was performed by keeping the protein concentration below $150 \mu \mathrm{M}$ all the way through purification. This behaviour is well in agreement with the available crystal structures of IscA which all indicate dimer formation but also indicates that the different species are in equilibrium with each other within the range of concentrations observed in the NMR samples. The best NMR sample in terms of spectral homogeneity was recorded on a $40 \mu \mathrm{M}$ sample directly obtained from size excluded chromatography selecting the sharp peak corresponding to the molecular weight of the monomer (Fig. 1b). This ${ }^{15} \mathrm{~N}$ HSQC spectrum had to be recorded with 128 scans to obtain sufficient signal-to-noise ratio. Unfortunately higher minimal concentration is needed for recording 3D spectra. For this purpose, we had to use $\sim 200 \mu \mathrm{M}$ samples. At this concentration, 160 of the expected 118 resonances were observed but their 

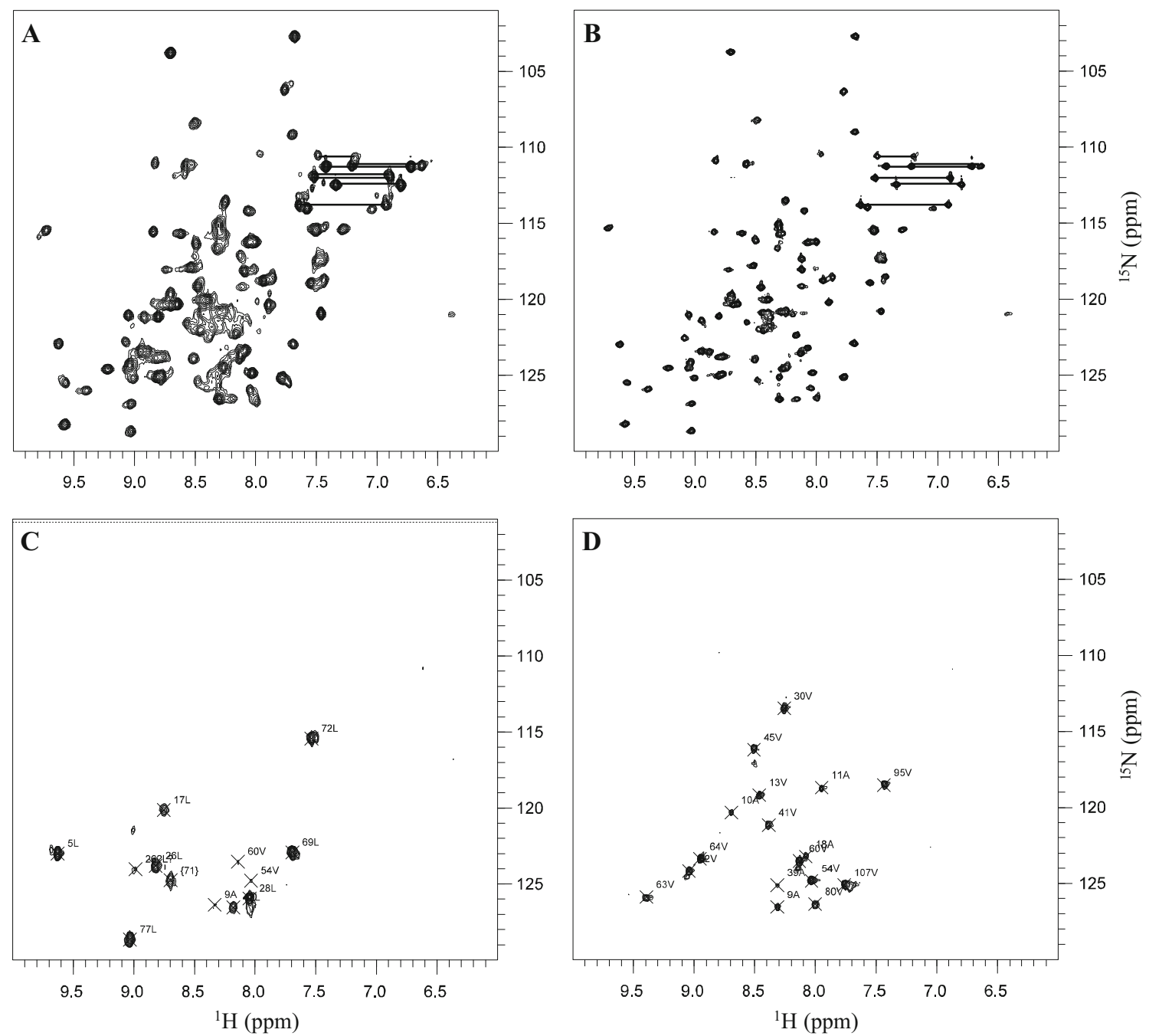

Fig. $1{ }^{1} \mathrm{H},{ }^{15} \mathrm{~N}$-HSQC spectra of the E. coli IscA protein recorded at $298 \mathrm{~K}$ on $600 \mathrm{MHz}$ spectrometer. a ${ }^{15} \mathrm{~N}$-uniformely labelled spectrum at a protein concentration of $200 \mu \mathrm{M}$. b ${ }^{15} \mathrm{~N}$-uniformely labelled spectrum under diluted conditions $(40 \mu \mathrm{M})$. c Selectively ${ }^{15} \mathrm{~N}$-leucine labelled spectrum at $100 \mu \mathrm{M}$ and $\mathbf{d}^{15} \mathrm{~N}$-valine selectively labelled

spectrum at $80 \mu \mathrm{M}$. Scrambling to alanine and valine respectively were observed in the valine and leucine ${ }^{15} \mathrm{~N}$ selectively labelled spectra. Peak doubles are indicated with primed numbers. The side chains of glutamines and asparagines are indicated by connecting lines

intensities were greatly differing reflecting populations. It is however important to stress that direct correlation between resonance intensity and populations in HSQC spectra is not possible since intensity is also strongly regulated by the flexibility of the specific amide group. We are not new to this behaviour as we had previously encountered a similar difficulty in the assignment of the AXH domain of ataxin-1 (de Chiara et al. 2013). To overcome the difficulties and properly trace the connectivities, we used various concentrations and several dilution/concentration experiments which allowed us to follow the heterogeneity of the sample. We also used selectively labelled schemes feeding the cells with specific labelled amino acids (i.e. ${ }^{15} \mathrm{~N}$ valine and leucine labelled samples;

Fig. 1c). These experiments confirmed and rectified previous assignment directing to a fully consistent solution tracing the most persistent and intense species.

Almost full backbone assignment of ${ }^{1} \mathrm{H},{ }^{13} \mathrm{C}$ and ${ }^{15} \mathrm{~N}$ of IscA was obtained as described below. Sequence specific ${ }^{1} \mathrm{HN},{ }^{15} \mathrm{~N},{ }^{13} \mathrm{C} \alpha,{ }^{13} \mathrm{C} \beta$ and ${ }^{13} \mathrm{C}$ assignment of the IscA spectrum was obtained using HNCA, HN(CO)CA, HNCO, $\mathrm{HN}(\mathrm{CA}) \mathrm{CO}$, HNCACB and $\mathrm{HN}(\mathrm{CO}) \mathrm{CACB}$ experiments (Muhandiram and Kay 1994) in combination with a 3D ${ }^{15} \mathrm{~N}$-edited NOESY-HSQC experiment. We managed to assign $87 \%$ of the backbone HN connectivities and 91, 84 and $83 \%$ of the $\mathrm{C} \alpha, \mathrm{C} \beta$ and $\mathrm{C}^{\prime}$ resonances respectively. Residues S2, G34, C35, S36, G37 could not be assigned because not observable in the spectra even though they 

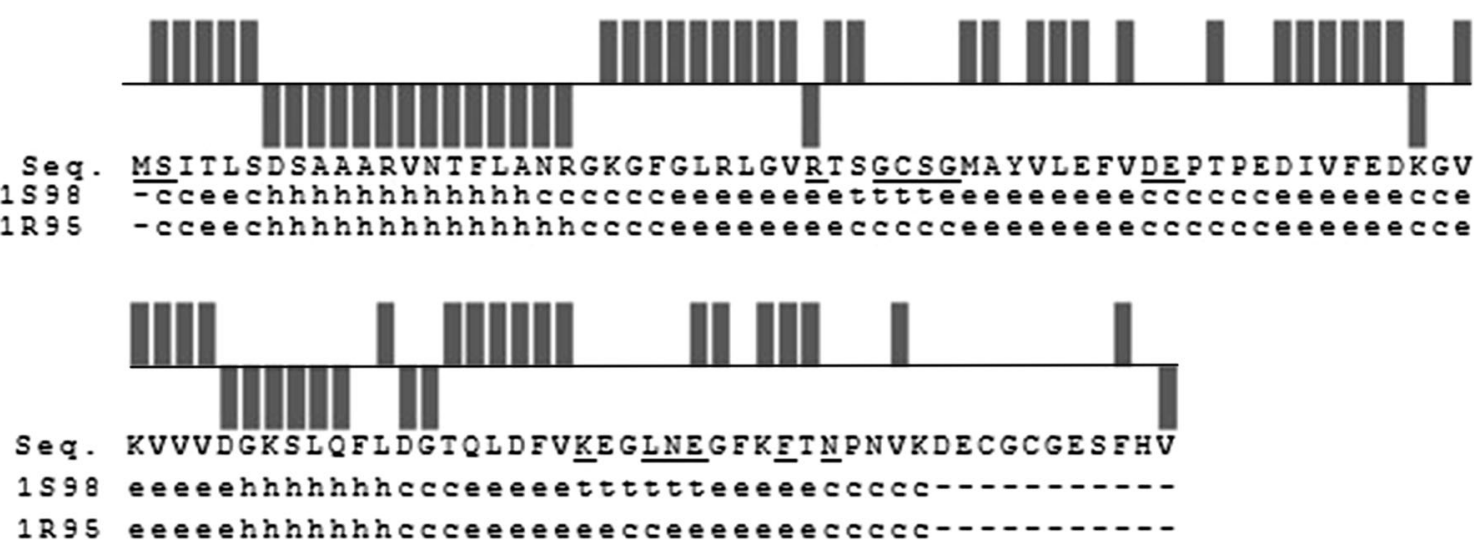

Fig. 2 Chemical shift indices obtained from $C^{\prime} \mathrm{C} \alpha$ and $\mathrm{C} \beta$ chemical shifts. The secondary structure indicated by these values is compared to that of two X-ray structures (1S98 and 1R95). Residues with nonassigned $\mathrm{NH}$ crosspeaks are underlined; regions not observed in the

should have well distinguishable $\mathrm{C} \alpha$ and/or $\mathrm{C} \beta$ resonances. We encountered a similar situation with L84 which could not be assigned even in the ${ }^{15} \mathrm{~N}$-leucine selectively labelled spectrum. Residues R31, D46, E47, K81, N85, E86, F90 and N92 could only be tentatively assigned because of the strong signal overlap and given that their sequential connectivities are interrupted by proline residues.

The ${ }^{1} \mathrm{H},{ }^{13} \mathrm{C}$ and ${ }^{15} \mathrm{~N}$ chemical shifts have been deposited to the BioMagResBank (BMRB) database and are available under the accession number 25912.

Secondary structure was predicted on the base of the ${ }^{13} \mathrm{C}$ chemical shifts using CSI calculation method (Wishart and Sykes 1994) integrated in the CCPN analysis program (Vranken et al. 2005; Fig. 2). Comparison with that of the X-ray structures $1 \mathrm{~S} 98$ and 1R95 shows an excellent agreement. Overall, these results put us in an excellent position to understand the specific role of IscA in ironsulfur cluster biogenesis and to study the interactions between IscA and other proteins.

Acknowledgments The authors thank the MRC Biomedical NMR Centre for technical support. The project was supported by MRC (Grant ref. U117584256) and EU (EFACTS and SARCOSI consortia). MP was the grateful recipient of a Newton fellowship from the Royal Society.

Open Access This article is distributed under the terms of the Creative Commons Attribution 4.0 International License (http://crea tivecommons.org/licenses/by/4.0/), which permits unrestricted use, distribution, and reproduction in any medium, provided you give appropriate credit to the original author(s) and the source, provide a link to the Creative Commons license, and indicate if changes were made.

\section{References}

Beinert H, Holm RH, Munck E (1997) Iron-sulfur clusters: nature's modular, multipurpose structures. Science 277:653-659 crystal structures are indicated as dash lines. Secondary structure indications use the Kabsh and Sander convention (Kabsch and Sander 1983)

Bilder PW, Ding H, Newcomer ME (2004) Crystal structure of the ancient, $\mathrm{Fe}-\mathrm{S}$ scaffold IscA reveals a novel protein fold. Biochemistry 43:133-139

Bonomi F, Iametti S, Ta D, Vickery LE (2005) Multiple turnover transfer of $\left[2 \mathrm{Fe}_{2} \mathrm{~S}\right]$ clusters by the iron-sulfur cluster assembly scaffold proteins IscU and IscA. J Biol Chem 280:29513-29518

Cupp-Vickery JR, Silberg JJ, Ta DT, Vickery LE (2004) Crystal structure of IscA, an iron-sulfur cluster assembly protein from Escherichia coli. J Mol Biol 338:127-137

de Chiara C, Rees M, Menon RP, Pauwels K, Lawrence C, Konarev PV, Svergun DI, Martin SR, Chen YW, Pastore A (2013) Selfassembly and conformational heterogeneity of the AXH domain of ataxin-1: an unusual example of a chameleon fold. Biophys $\mathrm{J}$ 104:1304-1313

Delaglio F, Grzesiek S, Vuister G, Zhu G, Pfeifer J, Bax A (1995) NMRPipe: a multidimensional spectral processing system based on UNIX pipes. J Biomol NMR 6:277-293

Ding H, Yang J, Coleman LC, Yeung S (2007) Distinct iron binding property of two putative iron donors for the iron-sulfur cluster assembly: IscA and the bacterial frataxin ortholog CyaY under physiological and oxidative stress conditions. J Biol Chem 282:7997-8004

Fogh R, Ionides J, Ulrich E, Boucher W, Vranken W, Linge JP, Habeck M, Rieping W, Bhat TN, Westbrook J, Henrick K, Gilliland G, Berman H, Thornton J, Nilges M, Markley J, Laue E (2002) The CCPN project: an interim report on a data model for the NMR community. Nat Struct Biol 9:416-418

Fontecave M (2006) Iron-sulfur clusters: ever-expanding roles. Nat Chem Biol 2:171-174

Johnson DC, Dean DR, Smith AD, Johnson MK (2005) Structure, function, and formation of biological iron-sulfur clusters. Annu Rev Biochem 74:247-281

Kabsch W, Sander C (1983) Dictionary of protein secondary structure: pattern recognition of hydrogen-bonded and geometrical features. Biopolymers 22:2577-2637

Krebs C, Agar JN, Smith AD, Frazzon J, Dean DR, Huynh RH, Johnson MK (2001) IscA, an alternate scaffold for Fe-S cluster biosynthesis. Biochemistry 40:14069-14080

Lill R (2009) Function and biogenesis of iron-sulphur proteins. Nature 460:831-838

Mettert EL, Kiley PJ (2015) How is Fe-S cluster formation regulated? Annu Rev Microbiol 69:505-526

Morimoto K, Yamashita E, Kondou Y, Lee SJ, Arisaka F, Tsukihara T, Nakai M (2006) The asymmetric IscA homodimer with an 
exposed $[2 \mathrm{Fe}-2 \mathrm{~S}]$ cluster suggests the structural basis of the $\mathrm{Fe}-$ S cluster biosynthetic scaffold. J Mol Biol 360:117-132

Muhandiram DR, Kay LE (1994) Gradient-enhanced triple-resonance three-dimensional NMR experiments with improved sensitivity. J Magn Reson 103:203-216

Ollagnier-de-Choudens S, Mattioli T, Takahashi Y, Fontecave M (2001) Iron-sulfur cluster assembly: characterization of IscA and evidence for a specific and functional complex with ferredoxin. J Biol Chem 276:22604-22607

Roche B, Aussel L, Ezraty B, Mandin P, Py B, Barras F (2013) Iron/sulfur proteins biogenesis in prokaryotes: formation, regulation and diversity. Biochim Biophys Acta 1827:455-469

Vranken WF, Boucher W, Stevens TJ, Fogh RH, Pajon A, Llinas M, Ulrich EL, Markley JL, Ionides J, Laue ED (2005) The CCPN data model for NMR spectroscopy: development of a software pipeline. Proteins 59:687-696
Wishart DS, Sykes BD (1994) The 13C chemical-shift index: a simple method for the identification of protein secondary structure using 13C chemical-shift data. J Biomol NMR 4:171-180

Xu XM, Moller SG (2011) Iron-sulfur clusters: biogenesis, molecular mechanisms, and their functional significance. Antioxid Redox Signal 15:271-307

Zeng J, Geng M, Jiang H, Liu Y, Liu J, Qiu G (2007) The IscA from Acidithiobacillus ferrooxidans is an iron-sulfur protein which assemble the $\left[\mathrm{Fe}_{4} \mathrm{~S}_{4}\right]$ cluster with intracellular iron and sulfur. Arch Biochem Biophys 463:237-244

Zheng L, Cash VL, Flint DH, Dean DR (1998) Assembly of ironsulfur clusters. Identification of an iscSUA-hscBA-fdx gene cluster from Azotobacter vinelandii. J Biol Chem 273:1326413272 